\title{
DE NOVO HISTOID LEPROSY WITH BORDERLINE TUBERCULOID LEPROSY: A RARE ASSOCIATION
}

\author{
Debajit Das ${ }^{1}$, Bhaskar Gupta루, Bornali Deka ${ }^{3}$
}

\section{HOW TO CITE THIS ARTICLE:}

Debajit Das, Bhaskar Gupta, Bornali Deka. "De Novo Histoid Leprosy with Borderline Tuberculoid Leprosy: A Rare Association". Journal of Evolution of Medical and Dental Sciences 2014; Vol. 3, Issue 24, June 16;

Page: 6633-6637, DOI: $10.14260 /$ jemds/2014/2794

\begin{abstract}
Histoid leprosy is an uncommon variant of lepromatous leprosy characterized by unique histopathological findings and characteristic bacterial morphology. It occurs in patients relapsing after dapsone monotherapy, in the presence of dapsone resistance or at times de novo. Though it is commonly seen in lepromatous leprosy, very rarely it may be seen in borderline and indeterminate leprosy. We report here a case of de novo histoid leprosy with borderline tuberculoid leprosy because of its rarity.
\end{abstract}

KEYWORDS: Histoid, borderline tuberculoid.

INTRODUCTION: Leprosy (Hansen's disease; Hanseniasis) is a chronic disease caused by Mycobacterium leprae, infectious in some cases and affecting the peripheral nervous system, the skin, and certain other tissues. ${ }^{1}$

Histoid leprosy first described by Wade (1963) is an uncommon variant of lepromatous leprosy. It is characterized by cutaneous and/ or subcutaneous nodules and plaques on apparently normal skin with unique histopathological findings and a characteristic bacterial morphology. It occurs in patients relapsing after dapsone monotherapy, in the presence of dapsone resistance or at times de novo. Apart from its occurrence in lepromatous leprosy, histoid lesions may rarely be seen in borderline ${ }^{2,3}$ and indeterminate leprosy. ${ }^{4}$ We report here a case of histoid leprosy in a 55 years old female with borderline tuberculoid leprosy.

CASE: A 55years old female presented to us with complaints of asymptomatic skin colored raised lesions on the right upper limb of 3months duration. She also complained of slight decrease in sensation in the anterolateral aspect of the right arm and hypopigmented macular lesions on both the cheeks which first appeared 6months ago. The patient noticed the skin colored lesions first over the right wrist joint which later increased in number to involve rest of the limb and a few coalesced to form a plaque on dorsum of right hand.

The patient also complained of low grade fever, malaise, swelling of the right upper limb for last 15days. Family history was non contributory. No history of any drug intake.

On examination, multiple shiny, non itchy, regular, dome shaped, skin colored nodules and a plaque over the right arm, elbow, radial side of right forearm and anterior aspect of the wrist were noted. On palpation, the nodules were non tender, firm in consistency measuring 1 to $2 \mathrm{cms}$. The nodules were present on apparently normal skin. The patient had well circumscribed hypoaesthetic, slightly hypopigmented plaque over the anterolateral aspect of the right arm measuring $5 \times 7 \mathrm{cms}$, and hypopigmented macular lesions over both the right and left cheek measuring $2.5 \times 3.5 \mathrm{cms}$ and $3 \times 4.5$ cms respectively. Right ulnar nerve was thickened. 
Cutaneous examination of rest of the body revealed no abnormality. Systemic examination was normal. Routine laboratory investigations were all within normal limit.

The slit skin smear from the nodules showed plenty of bacilli, with a bacteriological index of $4+$, while the slit skin smear from the hypoaesthetic hypopigmented lesions revealed no bacilli.

Histopathology of the dome shaped nodules showed atrophic epidermis with subepidermal grenz zone. The dermis showed sheets of round-to-spindle shaped histiocytes compressing the skin appendages. These spindle cells were arranged in whorled pattern. The Fite Faraco stain showed numerous uniformly stained bacilli. Histopathology from the hypoaesthetic patches showed granulomas following the neurovascular bundles and not infiltrating into the epidermis.

A final diagnosis of histoid leprosy with borderline tuberculoid leprosy was made.

The patient has been put on multibacillary multi drug therapy and is on regular follow up.

DISCUSSION: The term "histoid leprosy" was first described by Wade in 1963. Histoid leprosy is so called because the microscopic appearance of the nodule shows spindle shaped cells resembling those in a dermatofibroma. ${ }^{5}$ The lesions of histoid leprosy thus closely resembles dermatofibroma and other histiocytic and fibrotic tumours. ${ }^{6}$ It is considered by some as a variant of lepromatous leprosy (LL) and by others as distinct entity. An overall occurrence of $1.2 \%$ was found amongst the LL patients by Sehgal and Srivastava in their study. ${ }^{7}$ There is male preponderance and the average age affected is between 21 and 40 years. ${ }^{8}$ Histoid leprosy is associated with dapsone resistance and with relapse after dapsone monotherapy. However, this manifestation of leprosy has also been reported in patients in whom relapse occurred in presence of supervised monthly dose of multidrug therapy and in patients without any treatment ${ }^{6,9}$ or in patients whose disease is relapsing because they have stopped treatment. ${ }^{10}$ Focal loss of immunity is thought to be the cause of the large bacillary load seen in histoid lesions. ${ }^{8,11}$

Typical lesions are multiple, discrete, shiny, smooth, painless succulent, globular, protuberant, firm, skin colored, cutaneous and or subcutaneous nodules, papules, and plaques on apparently normal skin. They are regular in contour with shiny and stretched overlying skin, at times with constriction around their bases. The subcutaneous nodules vary in size but seldom greater than $5 \mathrm{cms} .{ }^{12}$ They do not extend deeply into the skin as an infiltration but feel like a button in superficial dermis. 5 The nodules may involve face, back, limbs and bony prominences, as well as mucous membranes in severely affected patients. Histoid lesions have also been reported to present along the course of the peripheral nerve trunks and cutaneous nerves. ${ }^{13}$ Classical histopathological findings include epidermal atrophy as a result of dermal expansion of the underlying leproma and a Grenz zone located immediately below the epidermis. ${ }^{6}$ The leproma consists of fusiform histiocytes arranged in a tangled or storiform pattern containing acid fast bacilli. There are three histologic variants of Histoid Hansens: Pure fusocellular, fusocellular with epithelioid component and fusocellular with vacuolated cells. The third pattern is most commonly observed. ${ }^{14}$

CONCLUSION: We present this case as occurrence of histoid leprosy with borderline tuberculoid leprosy which is a rare association. Early diagnosis and treatment of such cases is essential as these patients have a high bacillary load and are a potential source of infection. Moreover this is necessary for elimination of leprosy. 


\section{CASE REPORT}

\section{REFERENCES:}

1. Jopling WH, McDougall AC edited Handbook of Leprosy, $5^{\text {th }}$ edition. 1996; page 1.

2. Ramanujam K, Ramu G. Wade's histoid lepromatous leprosy. Report of a clinical study. Lepr India 1969; 41: 293-97.

3. Bhutani L.K, Bedi TR, Malhotra YK et al. Histoid leprosy in north India. Int J Lepr other Mycobact Dis 1974; 42: 174-81.

4. Ramanujam K, Ramu G. Histoid transformation from unstable forms of leprosy. Abstract of Congress Papers 17/ 335. Int J Lepr 1963, 41: 685.

5. Pfaltzgraff R.E, Ramu G. Clinical leprosy. In. Robert C Hastings edited 'Leprosy'; 1994. 2 ${ }^{\text {nd }}$ edition. P237-290.

6. Shaw IN, Ebenezer G, Rao GS, Natrajan MM, Balasundaram B. Relapse as histoid leprosy after receiving multidrug therapy (MDT); a report of three cases. Int J Lepr Other Mycobact Dis 2000; 68: $272-6$

7. Sehgal VN, Srivastava G. Histoid leprosy - a prospective diagnostic study in 38 patients. Dermatologica, 1988; 177; 212-217.

8. Kalla G, Purohit S, Vyas MC. Histoid, a clinical variant of multibacillary leprosy: Report from socalled nonendemic areas. Int J Lepr Other Mycobact Dis 2000; 68:267-71.

9. Ebenezer GJ, Barkataki A, Job CK. Leprosy relapse presenting in a histoid form after multidrug therapy. Br J Dermatol 1999; 140:759-60

10. Jopling WH, Mc Dougall AC edited Handbook of Leprosy. $5^{\text {th }}$ edition 1996, P35-36.

11. Job CK, Chacko CJG, Taylor PM. Electron microscopic study of Histoid leprosy with special reference to histogenesis. Leprosy in India 1997; 49: 467-470.

12. Sehgal V.N, Srivastava G. In. IAL Textbook of Leprosy, Histoid leprosy: 167-75.

13. Weidmann MV, Argento CM, Garramuno R. Lepra histoire deWade. Arch Argent Dermatol 2001; 51:235- 7.

14. Manoharan R, Madhu R, Srinivasan MS. Histoid Hansen: A case Report. J Indian Soc Teledermatol 2008; 2:12-6.

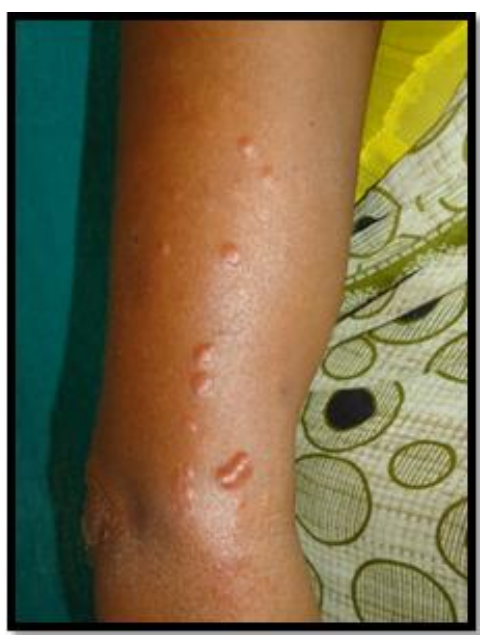

Fig. shows dome shaped histoid lesions on right arm

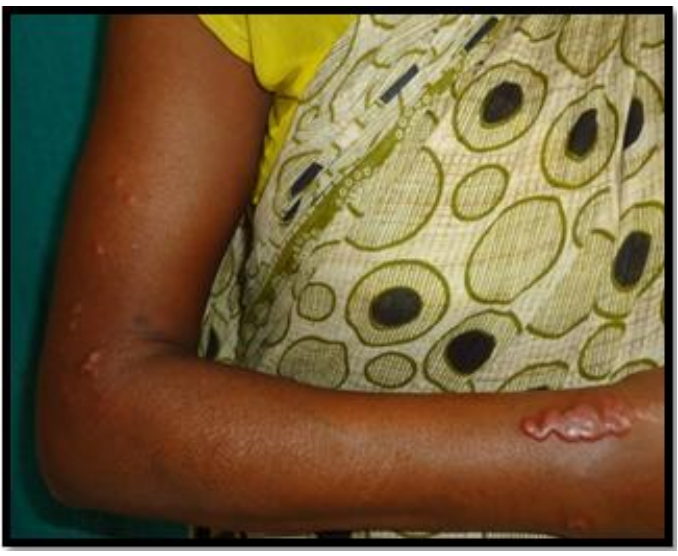

Fig. shows nodules coalesced to form plaque. 


\section{CASE REPORT}

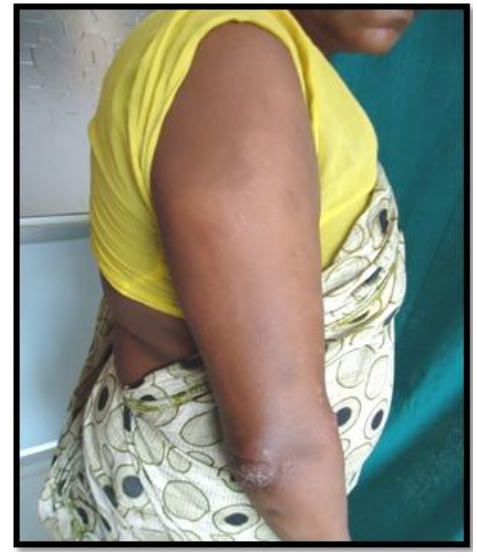

Fig. shows a large borderline tuberculoid plaque over right arm

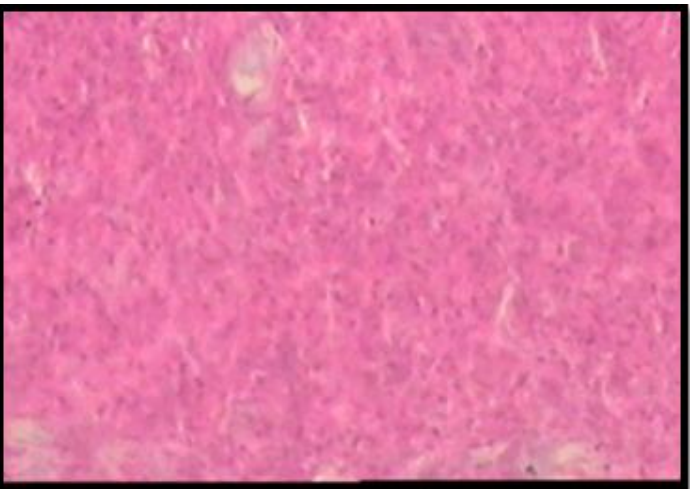

Fig. H and E stain showing spindle shaped cells in a whorled pattern of a histoid

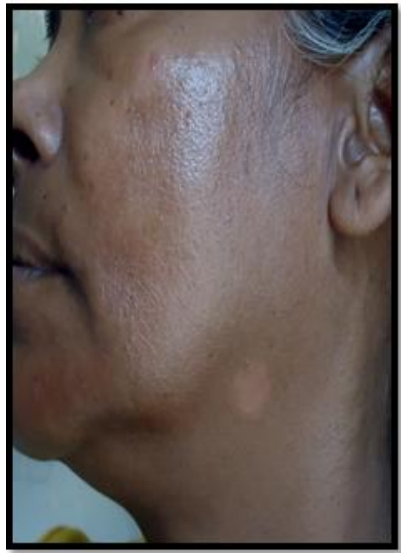

Fig. showing patch over left cheek and below the mandible

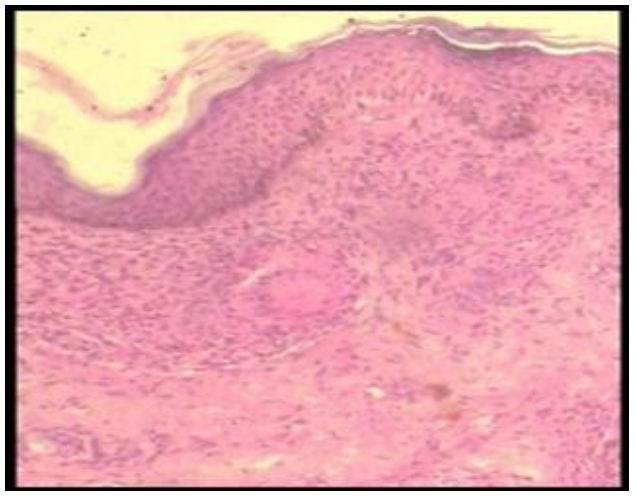

Fig. shows epithelioid cell granuloma Not infiltrating the epidermis, with a narrow free

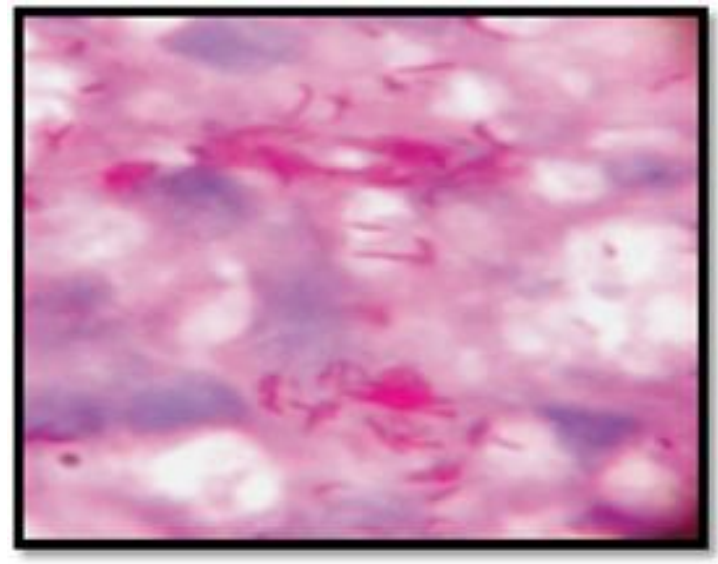

Fig. showing fite faraco staining of M.leprae 


\section{CASE REPORT}

\section{AUTHORS:}

1. Debajit Das

2. Bhaskar Gupta

3. Bornali Deka

\section{PARTICULARS OF CONTRIBUTORS:}

1. Associate Professor, Department of Dermatology, Silchar Medical College and Hospital.

2. Professor, Department of Dermatology, Silchar Medical College and Hospital.

3. Post Graduate Trainee, Department of Dermatology, Silchar Medical College and Hospital.

\section{NAME ADDRESS EMAIL ID OF THE} CORRESPONDING AUTHOR:

Dr. Debajit Das,

Department of Dermatology,

Silchar Medical College and Hospital,

Silchar-788014, Assam.

E-mail: debajit.smc@gmail.com

Date of Submission: 28/05/2014.

Date of Peer Review: 29/05/2014.

Date of Acceptance: 07/06/2014.

Date of Publishing: 12/06/2014. 